\title{
Особенности синтаксической организации и пунктуации в рекламном тексте рубежа XIX-XX вв. (на примере региональной прессы)
}

Ключевые слова: сокращение, текстовая организация, пунктуация, синтаксис, реклама. Key words: abbreviation, text organization, punctuation, syntax, advertising.

\begin{abstract}
The article deals with the syntactic organization and punctuation in advertising texts at the turn of the $19^{\text {th }}$ and $20^{\text {th }}$ centuries. The research material were advertising texts and advertisements placed in regional press ("Ural life", "Irbit fair leaf", etc.). During the period under review, print advertising is at the stage of formation and has not yet emerged as an independent genre. Modern advertising texts are primarily focused on attracting attention. They should be readable by a potential buyer without any difficulty, therefore, their syntax, punctuation, font and illustrative design should contribute to ease of perception and understanding of the text. In the considered material, the opposite situation is observed. With regard to its genre, advertising at the turn of the $19^{\text {th }}$ and $20^{\text {th }}$ centuries is close to announcements and aims to convey important information. The desire of the seller/manufacturer to tell as much as possible about their product to the buyer results in complexity of the text. Organization of advertising text at the turn of the $19^{\text {th }}$ and $20^{\text {th }}$ centuries involves an active use of abbreviations, complex syntactic constructions as well as unusual design elements (for example, a line break). Syntactic organization of the text at the given period can become an indicator of a gradual transition from the announcement genre to the ad genre: the texts most rich in information, still drifting towards the announcement genre, have complex punctuation and syntactic organization, while texts focused on the emotional response of the reader (a new stage in the development of the ad genre), on the contrary, are distinguished by considerable simplifications.
\end{abstract}

Важная характеристика рекламы как жанра на рубеже XIX-XX вв. - это отсутствие четких жанровых рамок. Реклама как самостоятельный жанр 
находится в процессе формирования, поэтому часто встает вопрос о критериях, которые позволят максимально однозначно говорить о том, относится текст к рекламе или нет. Опираясь на определения рекламы, данные в словарях ${ }^{1}$ и ряде исследований ${ }^{2}$, мы выделили следующий критерий: наличие в тексте элементов (хотя бы одного), специально нацеленных на увеличение читательской заинтересованности. Этот момент значим, так как указывает на интенцию воздействовать на читателя, а не только информировать его. При этом такие элементы могут быть как текстовыми, так и относящимися к оформлению (шрифтовому или иллюстративному) рекламного текста. Например, выделение текста декоративной рамкой или использование различных шрифтов в оформлении (рис. 1) указывают на стремление автора заинтересовать читателя, привлечь его внимание, сделать текст более заметным на газетной полосе.

\section{Рисунок 1}

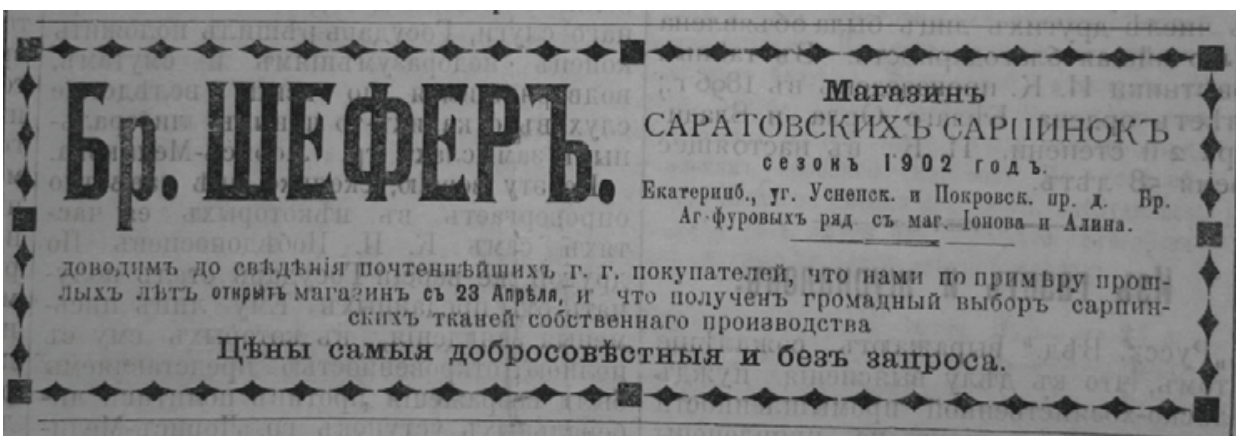

Привлечение внимания покупателя воплощается на всех уровнях текстовой организации, в первую очередь на уровне лексики и синтаксиса. О последнем мы и будем говорить в настоящей работе.

Для изучения синтаксической организации и особенностей использования сокращений в рекламных текстах рубежа XIX-XX вв. было проанализировано 760 неповторяющихся рекламных объявлений. Материал был взят из следующих региональных изданий: «Екатеринбургская неделя» (1891 г.),

1 Ср.: «Реклама - 1) Только ед. Мероприятия, имеющие целью широкое оповещение о чем-либо для привлечения потребителей, покупателей. 2) Плакат, объявление, служащие средством привлечения к чему-либо покупателей, потребителей» [BAS: 1182];

«Реклама - 1) Широкое оповещение о потребительских свойствах товаров и различных видах услуг с целью создания спроса на них. 2) Объявление, плакат, содержащие такое оповещение» [MAS: 702].

2 CM. [Bartra et al. 1999; Livšic 1999; Makašina 1995; Rozental', Kohtev 1981; Učenova, Staryh 2002]. 
«Ирбитский ярмарочный листок» (1893 г.), «Деловой корреспондент» (1894 г.), «Уральская жизнь» (1902-1903, 1907, 1909, 1916 гг.), «Екатеринбургская газета» (1906 г.), «Уральский листок» (1916 г.).

Работа посвящена текстам, типичным для рассматриваемого периода, т.е. прежде всего текстам с информативной либо экспрессивной доминантой. В каждой из этих групп можно выделить 2 подгруппы: краткие и развернутые. Синтаксическая организация внутри этих подгрупп существенно отличается.

Для кратких текстов характерно оформление текста одним-тремя простыми, обычно неосложненными, предложениями, в которых содержится вся необходимая информация (название товара, название фирмы-производителя или продавца, основные характеристики товара, адрес магазина) (рис. 2, 3). Границы предложения не всегда обозначены знаками препинания, вместо них могут использоваться оформительские приемы: деление на строки, шрифтовое выделение, использование заглавных букв, которые не обозначают начало предложения, а только выделяют начало новой строки (рис. 4, 5).

\section{Рисунок 2}

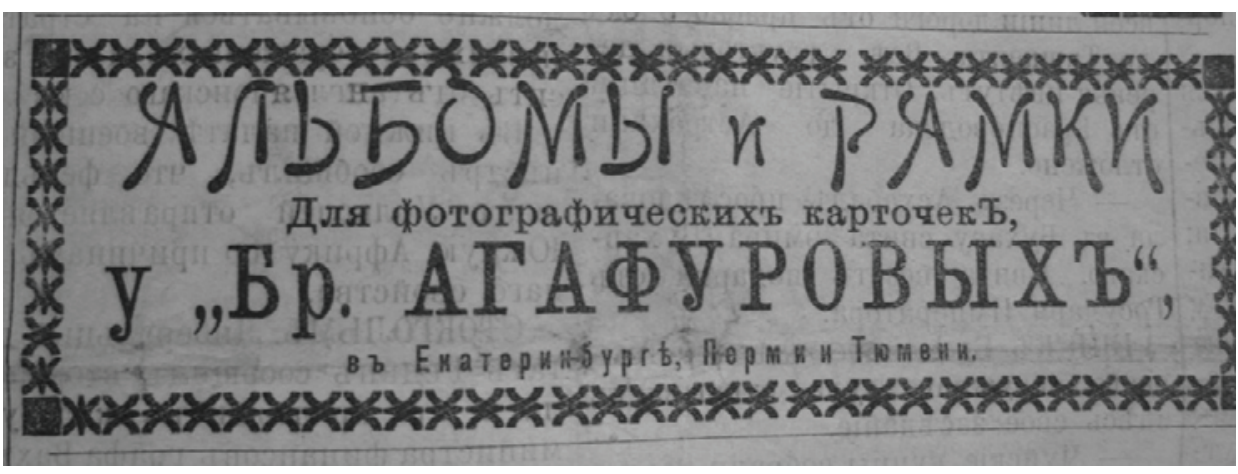

Для развернутых текстов с информативной доминантой характерно подробное описание товара с использованием сложных синтаксических конструкций. Часто можно увидеть небрежность в пунктуационном оформлении конструкций. Она выражается или в отсутствии знаков препинания там, где они необходимы, или, наоборот, в использовании лишних. Рассмотрим пример развернутого рекламного текста с информационной доминантой, для этого обратимся к афише электро-сине-фото-театра (рис. 6). Достаточно объемный текст состоит из двух предложений.

Вот первое из них: «Представлены будутъ в краскахъ живые изображенія в натуральную величину удивительнъйших феерических превращений, исполняемых первоклассными артистами и артистками Парижских театров цирков и кафе-концертов, самыми лучшими иллюзионистами и трансформаторами 
в мірђ танцорами акробатами и др. съ полной иллюзіею действительной жизни и непрерывного явлениія на экране воспроизводя съ полною точностью всъ главные чудеса и рБдкости парижской всемірной выставки 1900 г.»

\section{Рисунок 3}

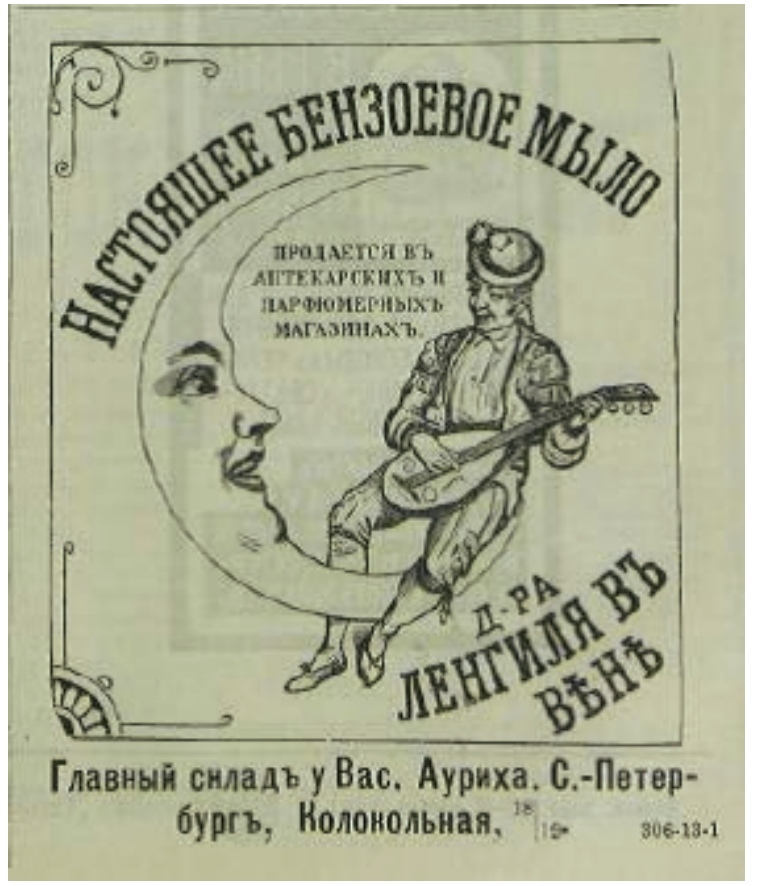

\section{Рисунок 4}

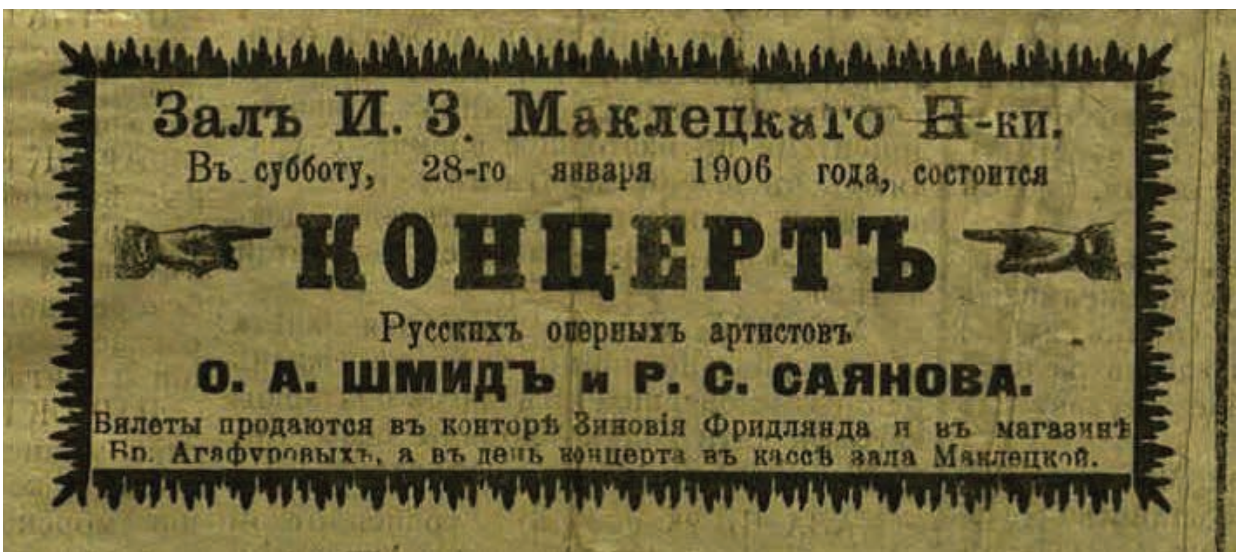




\section{Рисунок 5}

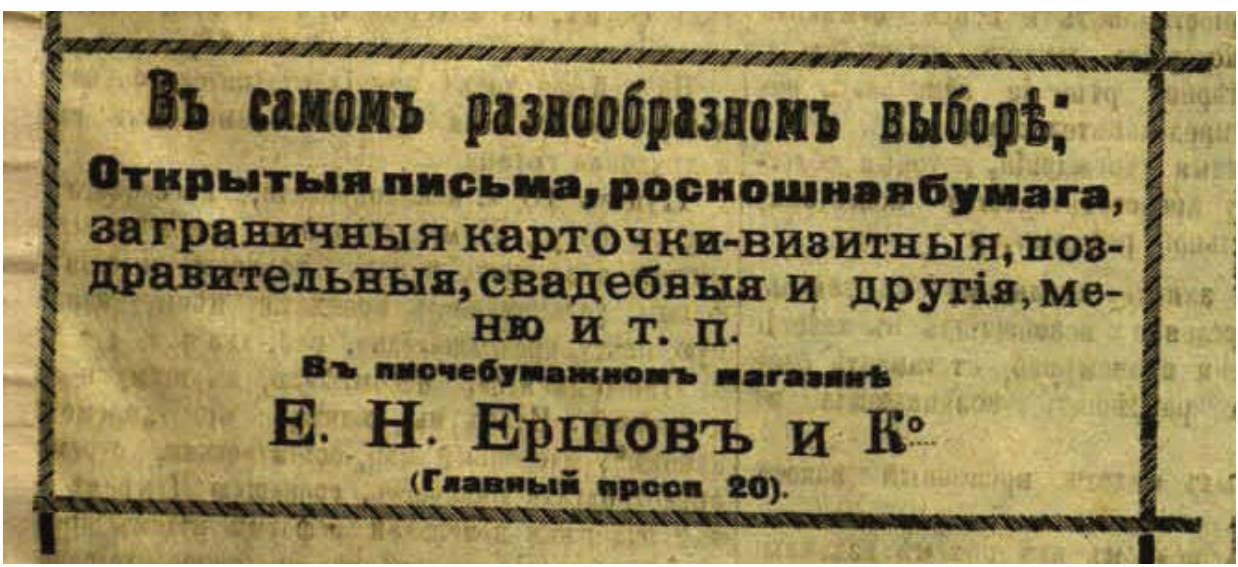

\section{Рисунок 6}

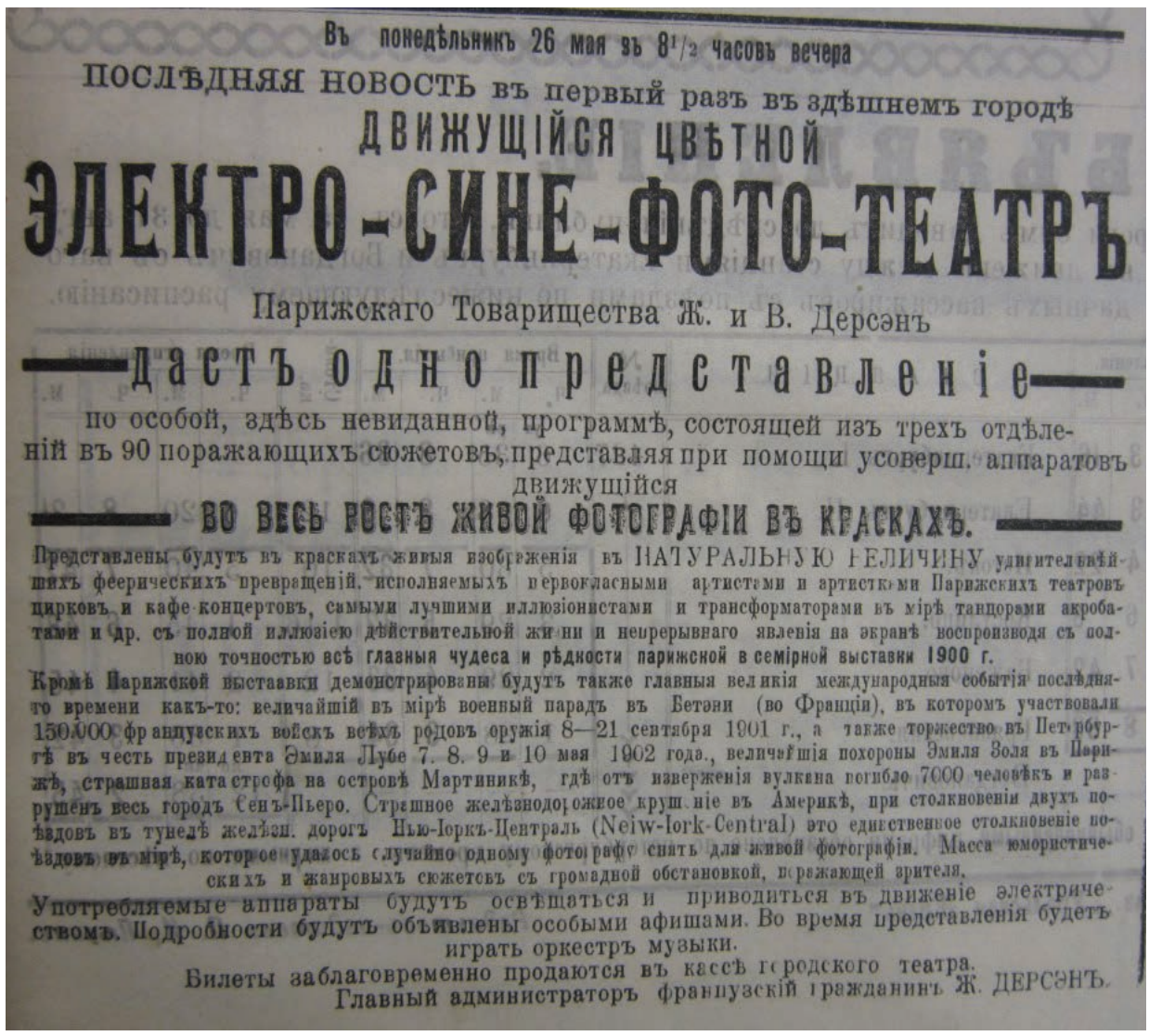


По структуре это простое предложение (подлежащее / субъект - изображения; сказуемое / предикат - представлены будут) с целым комплексом осложнений: 1) причастный оборот («исполняемых первоклассными артистами и артистками Парижских театров цирков и кафе-концертов, самыми лучшими иллюзионистами и трансформаторами в мірђ танцорами акробатами и др.»); 2) деепричастный оборот («воспроизводя съ полною точностью всь главные чудеса и ръдкости парижской всемірной выставки 1900 г.»); 3) несколько рядов однородных членов («артистами и артистками», «театров, цирков и кафе-концертов», «самыми лучшими иллюзионистами и трансформаторами в мире танцорами акробатами и др.», «действительной жизни и непрерывного явления на экране», «чудеса и редкости»). Осложнения служат для более точного и полного описания рекламируемого события, что приводит к значительной перегруженности текста.

Текст продолжается еще одним предложением, также распространенным: «Кроме Парижской выставки демонстрированы будутъ также главныя великія событія посльдняго времени какъ-то: величайшій в мірђ военный парад въ Бетони (во Франціи), въ которомъ участвовали 150000 французскихъ войскъ всехъ родовъ оружія 8-21 сентября 1901 г., а также торжество въ Петербургъ въ честь президента Эмиля Лубе 7. 8. 9 и 10 мая 1902 года., величайшія похороны Эмиля Золя въ Парижъ, страшная катастрофа на острове Мартиникъ, гдъ от изверженія вулкана погибло 7000 человъкъ и разрушенъ весь город Сенъ-Пьеро».

Это сложное предложение с сочинительной и подчинительной связью, с четырьмя основами (события демонстрированы будут; участвовали; город разрушен; погибло) и определительным придаточным. Также предложение осложнено рядами однородных членов (главные / великие; парад / торжество / похороны / катастрофа).

Использование конструкций с однородными членами предложения характерно для двух подгрупп рекламных текстов (краткие и развернутые тексты с информативной доминантой). Чаще всего ряды однородных членов просто включаются в простые или сложные предложения, как это сделано в рассмотренных выше примерах. Однако можно увидеть и другой способ: список, состоящий из простых предложений (рис. 7).

Перечисленные особенности, а именно использование простых предложений с большим количеством распространителей (придаточных разных типов, рядов однородных членов) характерны и для текстов с экспрессивной доминантой. Главное их отличие от текстов с информативной доминантой наблюдается на лексическом уровне: использование оценочной лексики, лексики с семантикой превосходности, высокого качества, уникальности и т.п. для описания товаров, событий, услуг.

Говоря о синтаксической организации рекламного текста, нужно обратить внимание на такой частотный элемент их текстового оформления 
как сокращения. Они содержатся в $70 \%$ объявлений. В первую очередь сокращаются единицы измерения стоимости, длины, веса, и т.п. (руб., коп., м., час., пуд.), обозначения типа торгового предприятия (О-во, Т-во, Ф-ка и т.д.). Такие сокращения общеизвестны и понятны каждому читателю газеты, просты в расшифровке и выполняют свою основную функцию информативное сжатие текста, уменьшая его объем без потери содержания. К особенностям их использования в рекламе рубежа XIX-XX вв. относится в первую очередь отсутствие унификации в рамках одного текста. Для текста этого периода нормально использование в разных строках формы к. и коп., р. и руб., ч. и час., С.-ПБ и С-Петербург или Спб и С.-Петербург, и проч. (рис. 8). Такая вариативность говорит об отсутствии редакторской работы с рекламными текстами. К общепонятным сокращениям можно отнести также обозначение титулов Императора и членов его семьи (рис. 9), причем эти сокращения тоже были вариативны.

\section{Рисунок 7}

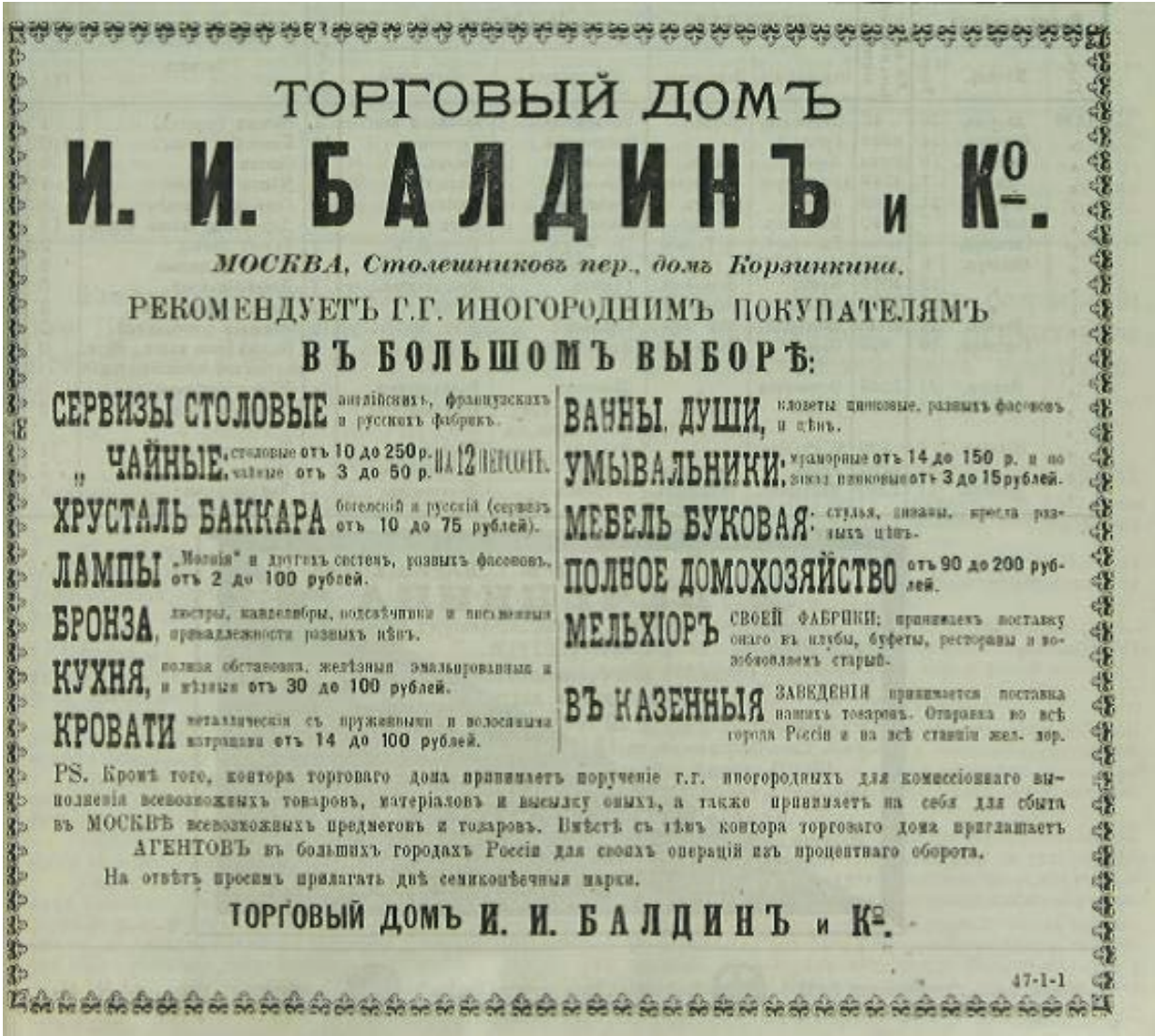




\section{Рисунок 8}

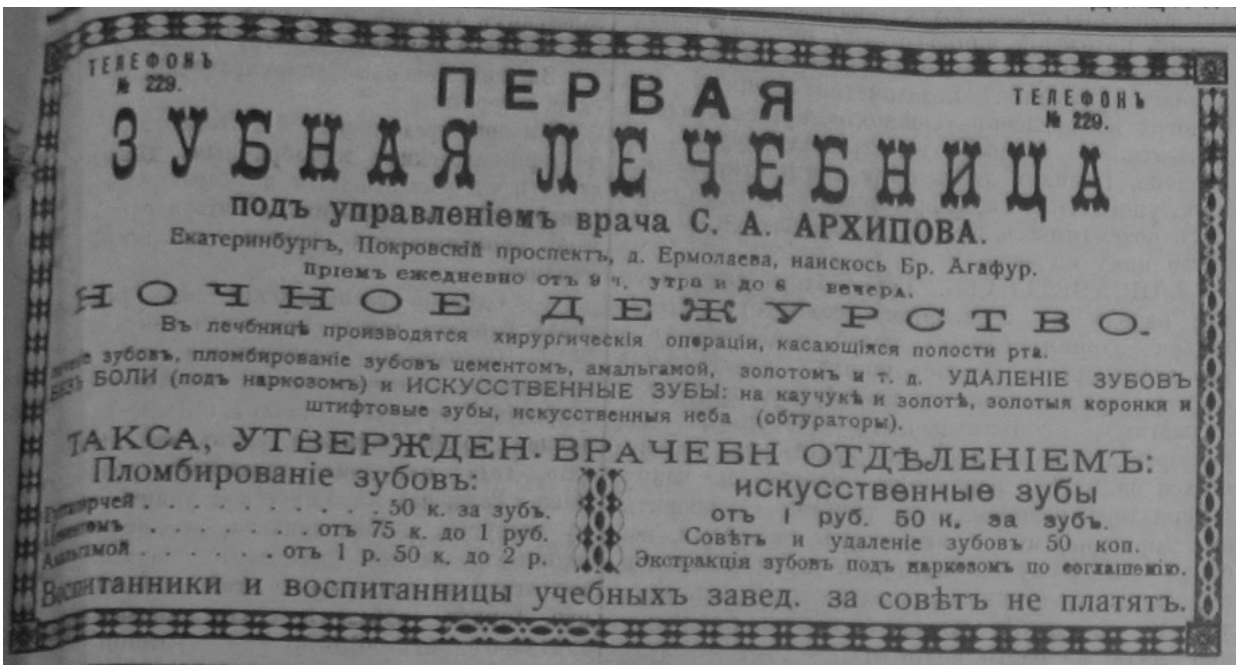

\section{Рисунок 9}

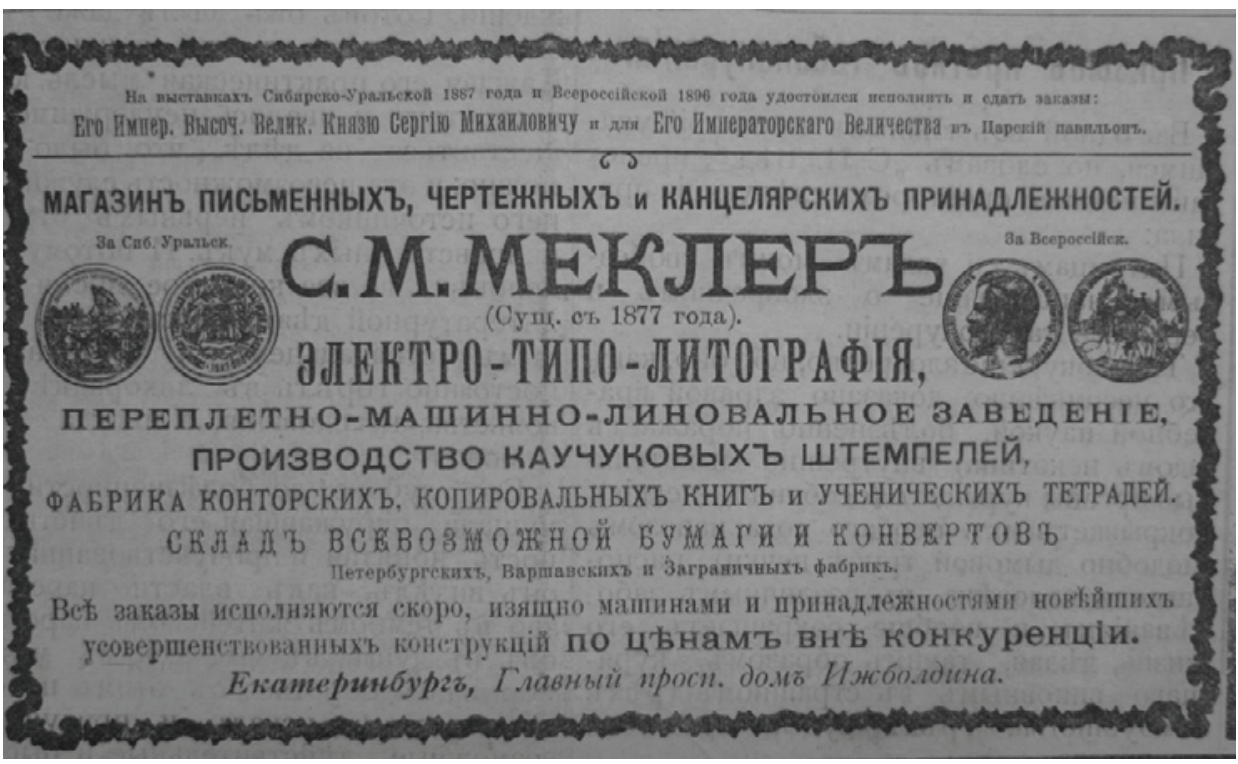

Обращает на себя внимание такая вариативность в рамках одного текста, когда речь идет о названиях городов, в особенности Санкт-Петербурга (С.-Петербург, СПБург, СПБ, С.-Петерб. и т.д.). Впрочем, именно для этого случая проще всего найти объяснение в текстовой организации: 
в большинстве случаев сокращения активно используются при оформлении адресного блока. Это логично, так как слова улица, проспект, дом, квартира, угол и т.д. понятны, а в контексте адресного блока тем более не требуют дополнительных пояснений. Часто в рекламном объявлении дополнительно указывался адрес для отправки телеграмм, который оформлялся более лаконично. Так в тексте могли появиться две формы сокращения одного и того же названия города.

Наряду с общепонятными сокращениями в рекламных текстах встречаются и окказиональные. Главная особенность таких сокращений - их ситуативное появление и использование. Это не устоявшиеся, а постоянно меняющиеся вслед за контекстом формы. Их появление в тексте не всегда оправданно. Например, сокращению могла подвергаться профессиональная лексика: Дамск. сапожки на 9 пуг. шагр. гамб. = Дамские сапожки на 9 пуговицах шагреневые гамбургские; Штиблеты шагр. союз. ам. лаку = Штиблеты шагреневые с союзкой американского лаку.

Выделяется несколько факторов, которые могли повлиять на появление оказиональных сокращений в рекламе.

1) В это время специализированных рекламных агентств было мало и далеко не все производители или продавцы считали необходимым прибегать к их услугам. Из этого следует, что очень часто мы имеем дело с непрофессиональными текстами, и в плане содержания, и в плане оформления. Поэтому то, что современный редактор исправил бы, в то время оставалось неизменным и печаталось.

2) Текст объявления также мог проходить редактуру непосредственно при печати. Во-первых, на рекламное объявление могло не хватить места, из-за чего текст приходилось сокращать. Во-вторых, сокращение текста могло быть связано и с изначальной экономией, так как меньшее по количеству знаков и месту на газетной полосе объявление стоило дешевле.

3) Автор часто прибегает к сокращению, например, повторяющихся слов или какой-либо информации, не относящейся непосредственно к описанию рекламируемого объекта, из-за желания включить в текст как можно больше информации о предлагаемом товаре, событии или услуге. Можно даже увидеть предложения, полностью состоящие из сокращений, например: Рисун. утв. Отд. пром. и торг. Мин. Ф. = Рисунок утвержден Отделом промышленности и торговли Министерства Финансов.

Однако такая подача рекламного текста, размещенного в массовой печати, может отпугнуть потенциального читателя / покупателя. Стремление дать максимальное количество информации о товаре / услуге / магазине, небольшая 
площадь газетного листа вынуждают использовать мелкий шрифт и сокращения, что мешает полноценному восприятию рекламы.

Несмотря на то, что основное различие в синтаксической организации наблюдается между краткими и развернутыми рекламными текстами, следует отметить разницу между текстами с информативной и экспрессивной доминантой. На синтаксическом уровне разница между этими группами не так велика, но уже начинает проявляться.

В первую очередь это появление в рекламе восклицательных предложений. В тексте выделяется наиболее значимая информация, например, о том, что рекламируемый товар является новинкой («Новость!», «Последняя новость!»), о чрезвычайно низкой цене на предлагаемый товар («Небывало дешевое развлеченіе!»). Восклицательные предложения могут придавать всему тексту общую интонацию восторженности, что можно увидеть, например, в афишах («Непостижимая тайна О! О! О!» в рекламе представлений артиста Роберта Ленца). Чаще всего по структуре это простые неполные назывные предложения. Обычно они располагаются в первой строке или рядом с иллюстрацией. В ряде текстов восклицательные предложения написаны на иностранном языке («Neu!»). Возможно усиление восклицания при помощи двух или трех восклицательных знаков в конце предложения.

Рассматривая синтаксическую организацию рекламных текстов, хочется обратить внимание на приемы, лежащие на границе текстового и иллюстративного его оформления. Это разрыв строк текста иллюстрацией (рис. 10) или размещение части текста на рисунке (рис. 11). Разрыв строки может проходить не только между словами (в полной или сокращенной форме), но и служить одновременно переносом слова. Текст на рисунке может частично дублировать информацию из основной части объявления, а может быть только не очень значимым для содержания дополнением. Оба эти приема в большей или меньшей степени нарушают целостность текста. Это еще один шаг в развитии рекламного текста, поиск гармоничного соотношения между привлекательным оформлением и понятным содержанием. В приведенном примере (рис. 10) этой гармонии еще нет.

Перечислим описанные особенности синтаксической организации рекламныХ текстов рубежа XIX-XX вв.

1. Можно говорить о двух группах рекламных текстов, различающихся по способу синтаксической организации: краткие и развернутые тексты.

2. Краткие рекламные тексты обладают простой синтаксической организацией. Обычно они состоят из неосложненных простых предложений, которые используются для передачи основной информации о рекламируемом товаре.

3. Развернутые рекламные объявления, нацеленные на подробный рассказ о товаре, продавце, производителе и т.п., имеют усложненную 


\section{Рисунок 10}

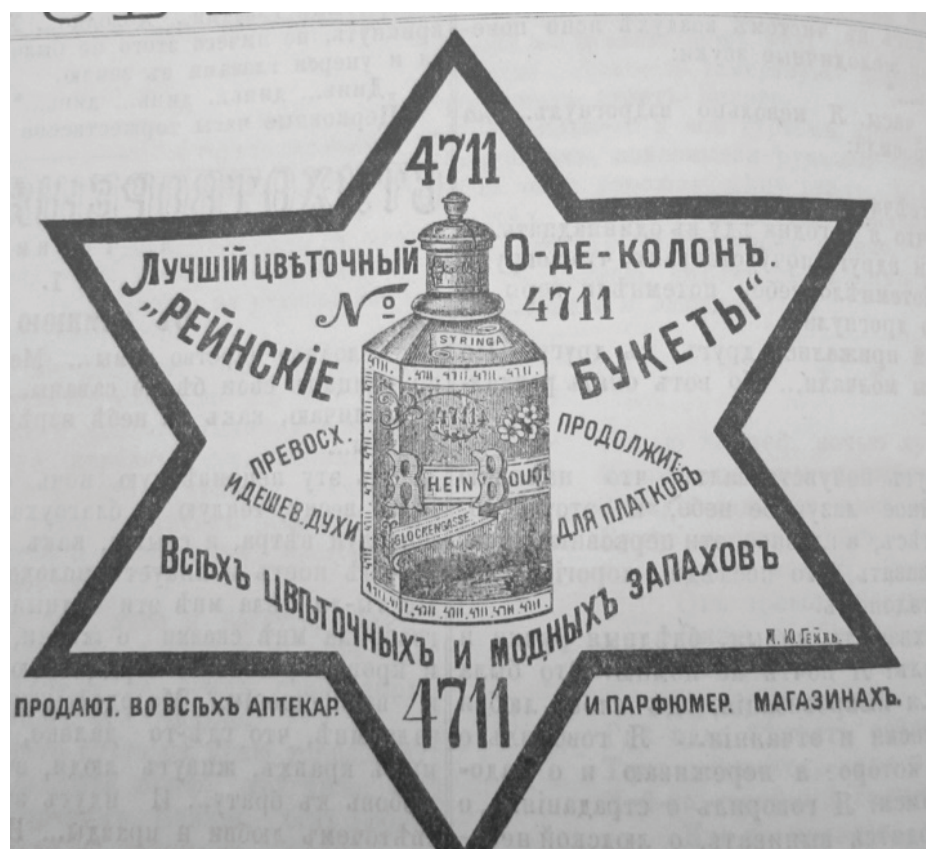

Рисунок 11

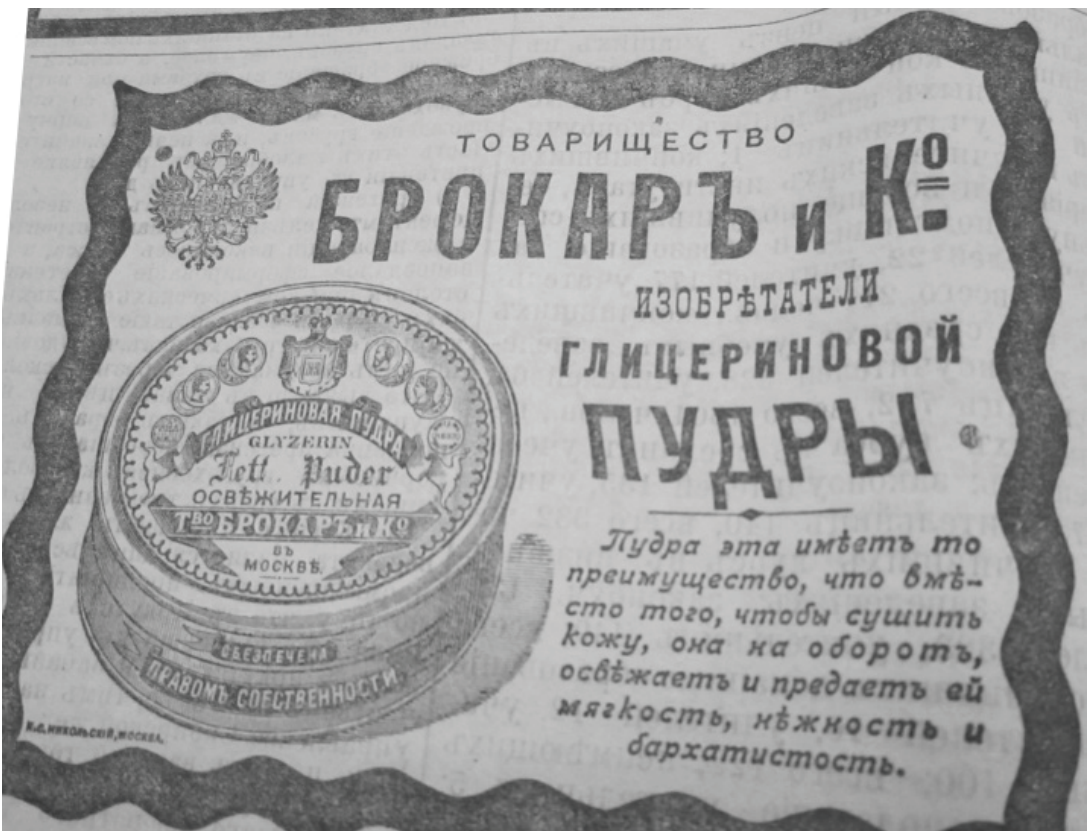


синтаксическую организацию. Часто встречаются тексты, полностью состоящие из сложных распространенных предложений с запутанной структурой и синтаксисом.

4. Начинают проявляться особенности синтаксической организации текстов с экспрессивной доминантой. В них появляются простые назывные восклицательные предложения, которые привлекают к тексту дополнительное внимание.

5. В рекламе рубежа XIX-XX вв. можно отметить две разнонаправленные тенденции в синтаксической организации текста: стремление к упрощению и стремление к усложнению. Стремление использовать короткие простые предложения и общепонятные сокращения делают текст более понятным для читателя, в то время как сложный синтаксис и обилие окказиональных сокращений, наоборот, создают проблемы для восприятия текста.

\section{Литература}

Alekseev D.I., Gozman I.G., Saharov G.V., 1983, Slovar'sokraŝenij russkogo âzyka, $3^{\text {rd }}$ ed., Moskva: Russkij âzyk.

Barinova S.O., 2007, Klassifikaciâ sokraŝenij v âzyke interneta (na materiale anglijskogo âzyka), Obŝestvennye i gumanitarnye nauki, 12 (33), pp. 24-27, https://cyberleninka. $\mathrm{ru} /$ article/n/klassifikatsiya-sokrascheniy-v-yazyke-interneta-na-materiale-angliyskogoyazyka/viewer; 10.09.2020.

Bartra R., Majers Dž., Aaker D., 1999, Reklamnyj menedžment, $5^{\text {th }}$ ed., Moskva; SanktPeterburg; Kiev.

BAS: Balahonova L.I., 2004, Bol'šoj akademičeskij slovar' russkogo âzyka, Moskva, Sankt-Peterburg: Nauka.

Livšic T.N., 1999, Specifika reklamy v pragmatičeskom i lingvističeskom aspektah, dis. kand. filol. nauk: 10.02.01. Moskva: RGB, 2005 (iz fondov Rossijskoj Gosudarstvennoj Biblioteki).

Makašina L.P., 1995, Russkaâ reklama. Otečestvennaâ praktika (1703-1918), Ekaterinburg: Izd-vo Ural'skogo universiteta.

MAS: Evgen'eva A.P. (ed.), 1987, Slovar'russkogo âzyka v 4 tomah (Malyj akademičeskij slovar'), vol. 3, Moskva: Russkij âzyk.

Rozental' D.È., Kohtev N.N., 1981, Âzyk reklamnyh tekstov: učeb. posobie dlâ vuzov po spec. «Žurnalistika», Moskva: Vysšaâ škola.

Švedova N.Û., 1980, Russkaâ grammatika, Moskva: Izdatel'stvo «Nauka».

Učenova V.V., Staryh N.V., 2002, Istoriâ reklamy, Sankt-Peterburg: Piter. 